\title{
Determining the market value of high-rise residential buildings based on evaluation of consumer properties
}

\author{
Svetlana Kolobova ${ }^{1^{*}}$ \\ Moscow State University of Civil Engineering, 26 Yaroslavskoye shosse, 129337, Moscow, Russia
}

\begin{abstract}
As you know, high-rise construction is an indicator of the practical implementation of advanced innovative technologies in the construction industry of the country. High-rise building inevitably comes to the big cities, in connection with the shortage and value of land. The life cycle of any construction project, including high-rise buildings consists of chains: of engineering survey - design-construction-operation. In the process of operation of a tall building, decisions about major repairs or reconstruction of a building are made for decision-making on further use. This article describes methods of assessing the consumer quality of high-rise residential buildings and the establishment of prices based on consumer characteristics of a tall residential building. It is proposed to assess the premises under their quality characteristics. The study was conducted to establish the influence of individual, comprehensive and integral indicators of comparable quality for effective quality living spaces. Simultaneously, there was established a relationship of quality with the consumer cost of housing, ultimately with the potential needs of owners, tenants of the home, lessor dwelling, or buyers of residential properties and other participants in the residential real estate market. This relationship further creates consumer requirements to quality standard of premises at a certain stage of socioeconomic development.
\end{abstract}

\section{Introduction}

In Russia the leaders of high-rise housing construction are the following Moscow construction companies: "Don-Stroy", Mirax Group, Mirax Park. High-rise residential buildings are already built in residential complexes of Moscow "Triumph - Palace", "Edelweiss", "Tricolor", "Continental", "Scarlet sails", "House on Mosfilmovskaya", "House in Sokolniki". Among the economy projects in construction there is a "Northern city", "Airbus", "Volga sails" and others. The demand for housing in high-rise buildings continues to evolve. Modern high-rise apartment buildings are constructed in such a way that you have a multi-level underground Parking. On the first two floors of multi-storey residential buildings there is a shopping centre. The hotel is located above the shopping centre . Apartments are located above the hotel. The top two floors are occupied by apartments and penthouses.

*Corresponding author: KolobovaSV@mgsu.ru 
Repair and reconstruction of residential development in the future will solve the issue of increasing the of consumer quality of real estate : apartments, houses, neighborhoods. Consequently, this will increase their competitiveness on the market. After the repair, residential properties have a higher assessed value compared to residential facilities, which were not repaired. It is proposed to undertake an assessment of the premises according to their quality characteristics. The study was conducted with the aim of establishing the influence of individual characteristics and indicators of quality to determine the overall (effective) quality of living spaces. Thus was established the connection of quality with the consumer cost of housing, ultimately with the potential needs of the owners, lessees, tenants or home buyers and other participants in the residential real estate market. This relationship creates a consumer demand for quality space at a certain stage of socio-economic development.

\section{Literature review}

The influence of consumer characteristics on the cost of housing and subsequent sales is studied by scientists of different countries. Assessment of the quality of housing in various countries are described in several scientific publications. For example, in the article "Data quality challenges in the UK social housing sector» authors Caroline Duvierac, Daniel Neagub, Crina Oltean-Dumbravaa and Dave Dickensc

explain that «The social housing sector has yet to realise the potential of high data quality» [1]. M. Norris is devoted his article to the study of the construction and management of the housing sector in the countries of Western Europe "Compared to the rest of the developed world, Western Europe is distinguished by relatively large social housing sectors».... However, institutional arrangements for the management, financing, and regulation of social housing have been commonly reformed since the 1970s. Object subsidies for the construction of new social housing have been cut and replaced by subject subsidies for tenants such as income-related housing allowances. As a result, new social housing construction has declined and the social profile of tenants has generally become more disadvantaged. In response, social landlords have devoted more attention to the social aspects of housing management and the regeneration of estates» [2]. A. Beer examines governance in the housing sector in developed economies : «Over recent decades, the management and delivery of housing assistance measures in many developed economies has become more complex as a wider range of actors have become involved in the sector» [3]. Emma R. continues the theme of the research management of the housing sector: "Through a case study of a small, affordable housing community in Sydney, Australia, it shows that housing governance can profoundly shape senses of home in aging, both contributing to and diminishing senses of home. Further, it points to a connection between housing governance and housing design with different housing typologies associated with different aging bodies and forms of management practice, with profound implications for residents' senses of home» [4].

The article discusses the influence of the quality of the workmanship and construction of new housing on sales prices and capital growth. To measure the quality of construction we use the unique situation in Singapore, where the newly completed residential projects are evaluated regardless of the quality of work in the framework of the quality evaluation system construction. «Empirical evidence suggests that apartments that are well constructed not only command a higher price for developers, but they also generate higher capital gains for homeowners and investors in the future» [ 5]. Other articles are devoted to the research to price discovery in the local housing market. The key question in scientific research is the quality of construction $[6,7,8,9]$. Russian scientists have also devoted their numerous scientific papers research housing.

$[10,11,12,13,14,15]$. 


\section{Materials and methods}

The author of this article found the concept of consumer quality and cost proposed method of determining this quality of housing.

To assess current market value we introduce the concept of integrated quality. Integral quality is determined by the set of all functional and economic indicators, it is through the relationship between consumer cost and the cost of a residential facility. Structure of consumer properties of objects of housing represented in Fig.1

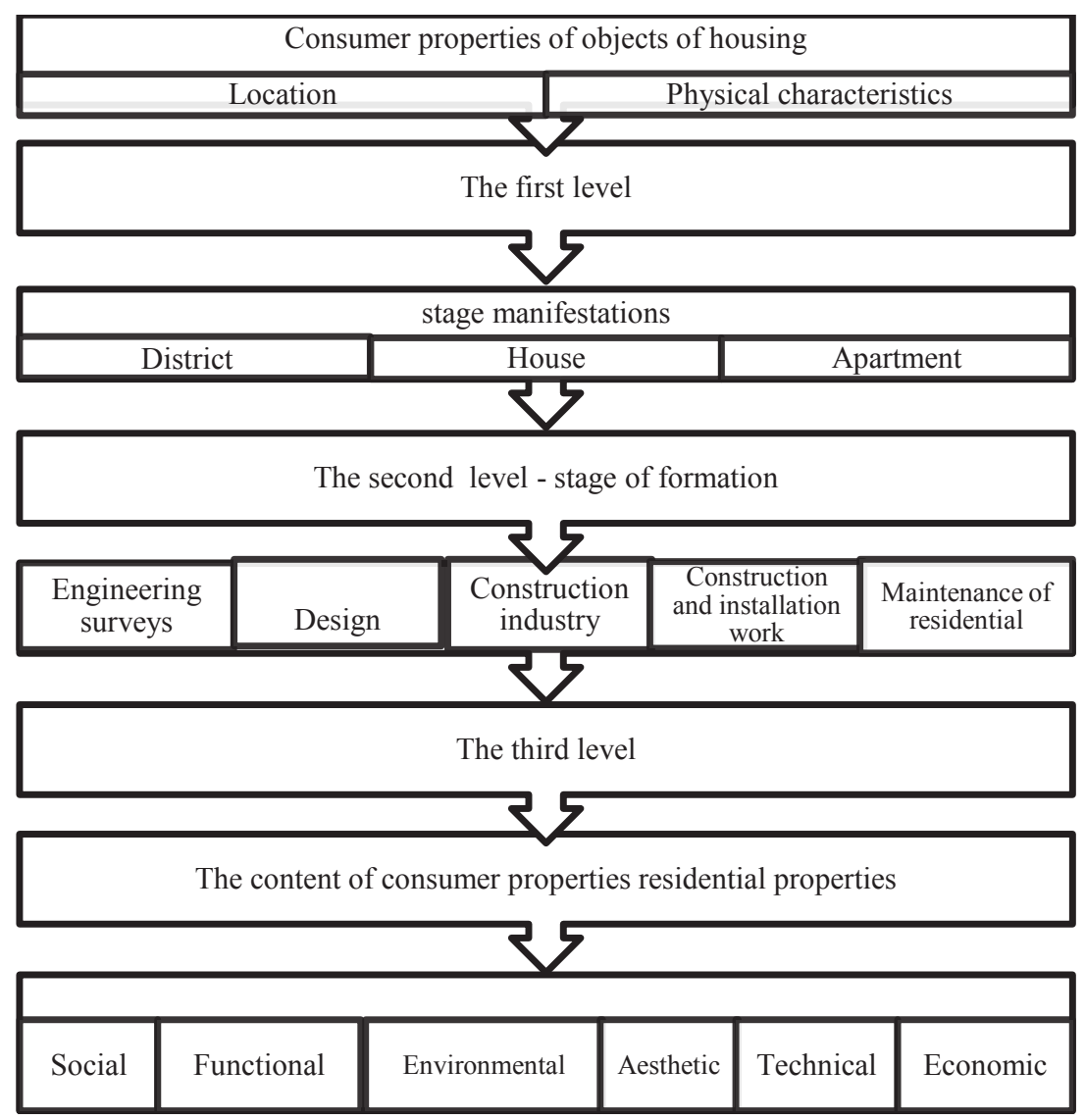

Fig.1. Structure of consumer properties of objects of housing

You must be able to measure consumer value of premises of different quality, that is, to set the level of quality. To measure the level of quality real estate by comparing it with a certain level of quality of the same object, taken as the base for comparison (the base quality). Based on this approach, the expression of quantitative relationships between the properties of a living object and the reflection of these properties in the process of operation of residential facility, namely, between the quality of construction and quality of maintenance and operation .

The number of indicators of the quality of any object, including living quarters, very large, and therefore requires the streamlining of these indicators, that is, their classification. As the basis of classification should be taken of the ability of indicators to Express the most characteristic groups of the object properties, the ability of quantitative and qualitative reflect 
these properties. Their set needs to determine the quality of the object. Their body needs to determine the quality of the object. For the dwelling is inherent to a certain group of properties, component quality standard: a group of environmental, functional, aesthetic, economic, technical and social properties. The system and composition of individual indicators to obtain a comprehensive characterization of the quality of the object, based on the analysis of scientific publications. The individual indicators of the quality of a residential facility must allow its assessment at three levels: district, house, apartment. Level of quality dwelling is a relative characteristic based on the comparison of the actual values of individual quality indicators (hereinafter IQI) residential facility $\left\langle P_{j} »\right.$ with the respective preset values baseline $« P_{J}^{b} »$.

Since the properties through the relevant IQI, forming a quality residential properties, differently involved in the formation of this quality, that is, have different weight, it must be considered in determining comprehensive indicators of the quality of the estimated residential units on each of three levels of manifestation of these properties: urban district, houses, apartments. The quantitative values of the IQI of the object in each level are comparable using the weight of the IQI. The definition of weight, the IQI is produced using a introduced by the author three-point rating scale from 0 to 2 points. IQI, which have a significant effect on the formation of consumer quality of residential facility, is assigned the highest score 2 , and IQI does not affect the consumer quality - 0 .

Introduced coding of indicators, reflecting the level of their manifestation and the number summarizes their properties:

- consumer quality of apartments -100 ;

- consumer quality at house - 200;

- consumer quality of district - 300.

Since the properties through the relevant IQI, forming a quality residential facilities differ from one another by its weight, i.e., importance in the overall assessment of its level of quality, then there is a need for integrated indicators valuation for each of the three levels of manifestation of these properties : urban district, houses, apartments.

Obtaining a comprehensive measure of consumer qualities of premises associated with the approach of the calculated quantitative values of object on each level to the total index, taking into account comparability of the estimates IQI and the assigned weights of IQI.

To establish the relative weights IQI residential premises were involved 11 experts in the field of transactions with residential real estate, with practical experience in the real estate market from 6 to 15 years. The experts who participated in the determination of the functional weighting of the IQI, set out the assessment in accordance with the importance of quality. The most significant IQI was awarded a perfect score of "2", and IQI does not affect the quality of the residential object " 0 ". In the processing of these data obtained the desired weight. Each expert was offered a questionnaire with tables. It was necessary to fill the table with given factors, "j" and IQI "Pj" to a residential facility.

An example of a questionnaire table for assessment factors given in table 1

Table 1. Evaluation of residential property.

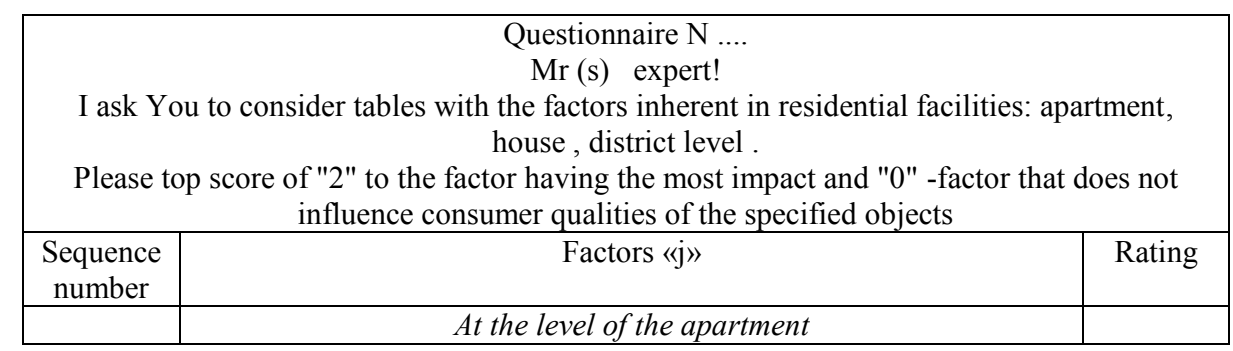




\begin{tabular}{|l|l|l|}
\hline 1 & The location of the apartment in the house & \\
\hline 2 & Space-planning solution of the apartment & \\
\hline 3 & The presence of the glassed balcony(s) & \\
\hline 4 & Combined bathroom (bathroom with toilet) & \\
\hline 5 & Improved furnish of premises under the "European standard" & \\
\hline 6 & Sanitary state & \\
\hline 1 & \multicolumn{1}{|c|}{ At the level of the house } & \\
\hline 2 & Space-planning decision of the house & \\
\hline 3 & The level of technical furnishing & \\
\hline 4 & The proximity to public transport & \\
\hline 5 & $\begin{array}{l}\text { The building belongs to the monuments of history, culture and } \\
\text { architecture }\end{array}$ & \\
\hline 6 & Shopping, office space on the first floor of the house & \\
\hline 1 & $\begin{array}{l}\text { The location of the location of the house relative to the center of the } \\
\text { city }\end{array}$ & \\
\hline 2 & The environment & \\
\hline 3 & The improvement district & \\
\hline 4 & The individuality of the area & \\
\hline
\end{tabular}

After filling in the experts table, is the processing of the obtained results. Initially it was determined the weight of characteristics at each of three levels of the house and area:

$$
m_{j}=\frac{\sum_{1}^{J} V_{j s}}{\sum_{1}^{J} \Sigma_{1}^{S} V_{j S}} \quad, \text { in this case } \sum_{1}^{J} m_{j}=1
$$

Where: $m_{j}$ - the weight characteristics «j»;

$V j s$ - the assessment, exhibited j-th characteristic of the s-th expert;

$\mathrm{j}=1, \mathrm{~J}-$ ordinal characteristics;

$\mathrm{s}=1, \mathrm{~S}-$ serial number expert.

For example, the weight factor $\left\langle j_{1} »\right.$ «The location of the apartment in the house» $m_{j_{1}}$ is as follows:

$$
m_{j_{1}}=\frac{\sum_{1}^{1} V_{j 1 s}}{\sum_{1}^{6} \sum_{1}^{11} V_{j 1 S}}=\frac{12}{66}=0.182
$$

Similarly, the calculation of the weights for other factors. Example and definition of weights for groups of factors for objects on the level are shown in table 2.

Table 2. Sample weights for groups of factors for objects on the level.

\begin{tabular}{|c|c|c|c|c|c|c|}
\hline Factor $\mathrm{j}$ & \multicolumn{6}{|c|}{ At the level of the apartment } \\
\hline & $\begin{array}{l}\text { The location of } \\
\text { the apartment in } \\
\text { the house }\end{array}$ & $\begin{array}{l}\text { Space- } \\
\text { planning } \\
\text { solution of } \\
\text { the } \\
\text { apartment }\end{array}$ & $\begin{array}{l}\text { The } \\
\text { presence of } \\
\text { the glassed } \\
\text { balcony (s) }\end{array}$ & $\begin{array}{l}\text { Combined } \\
\text { bathroom } \\
\text { (bathroom } \\
\text { with toilet) }\end{array}$ & $\begin{array}{l}\text { Improve } \\
\text { d furnish } \\
\text { of } \\
\text { premises } \\
\text { under the } \\
\text { "Euro- } \\
\text { standard" }\end{array}$ & $\begin{array}{l}\text { Sanitary } \\
\text { state }\end{array}$ \\
\hline 1 & 1 & 2 & 1 & 0 & 0 & 2 \\
\hline 2 & 1 & 2 & 1 & 1 & 0 & 0 \\
\hline 3 & 2 & 1 & 1 & 1 & 0 & 2 \\
\hline 4 & 0 & 2 & 1 & 1 & 1 & 1 \\
\hline 5 & 2 & 1 & 2 & 0 & 0 & 0 \\
\hline 6 & 1 & 1 & 2 & 2 & 1 & 0 \\
\hline
\end{tabular}




\begin{tabular}{|c|c|c|c|c|c|c|}
\hline 7 & 2 & 1 & 1 & 0 & 1 & 1 \\
\hline 8 & 1 & 2 & 0 & 1 & 0 & 2 \\
\hline 9 & 0 & 2 & 1 & 1 & 0 & 2 \\
\hline 10 & 1 & 1 & 2 & 1 & 2 & 0 \\
\hline 11 & 1 & 0 & 1 & 1 & 0 & 2 \\
\hline$\sum_{1}^{11} V_{j s}$ & 12 & 15 & 13 & 9 & 5 & 12 \\
\hline$m_{j}$ & 0.182 & 0.227 & 0.197 & 0.136 & 0.076 & 0.182 \\
\hline \multicolumn{6}{|l}{} \\
$\sum_{1}^{6} m_{j}=0.182+0.227+0.197+0.136+0.182+0.076=1$ \\
\hline
\end{tabular}

Similarly one computes the values of weights at the house and the area.

Then in the same way the weight IQI - «P $P_{j} »$ in each group of characteristics:

$$
m_{P_{j}}=\frac{\sum_{1}^{P} V_{P_{j}} s}{\sum_{1}^{P} \sum_{1}^{S} V_{P_{j}} S}, \text { in this case } \sum_{1}^{P} m_{P_{j}}=1
$$

Where $m_{P_{j}}-$ - weight IQI $\ll P_{j} » ; V_{P_{j} S}-$ the mark awarded $P_{j}$-th IQI s -th expert.

Weigh $m_{P_{j}}$ is calculated by multiplying the weight $m_{P_{j_{S}}}$ on the weight characteristic «j» weight $m_{j}$. For example, $m_{P_{1}}=0.182$. $0.182=0.033$

$m_{P_{2}}=0.227 \cdot 0.182=0.041$
$m_{P_{3}}=0.197 \cdot 0.182=0.036$
$m_{P_{4}}=0.212 \cdot 0.182=0.039$
$m_{P_{5}}=0.182 \cdot 0.182=0.033$

\section{Results}

Example the definition of weights $m_{P_{j}}$ and the average marks $q_{P_{j}}$ at the level of the apartment the factors "the location of the apartment in the house" and "Space-planning solution of the apartment" are shown in table 3.

Table 3. Example the definition of weights $m_{P_{j}}$ and the average marks $q_{P_{j}}$ at the level of the apartment the factors "the location of the apartment in the house" and "Space-planning solution of the apartment".

\begin{tabular}{|c|c|c|c|c|c|c|c|c|c|c|c|}
\hline Factor $\mathrm{j}$ & \multicolumn{5}{|c|}{$\begin{array}{c}\text { The location of the apartment in the } \\
\text { house }\end{array}$} & \multicolumn{6}{|c|}{$\begin{array}{c}\text { Space-planning solution of the } \\
\text { apartment }\end{array}$} \\
\hline 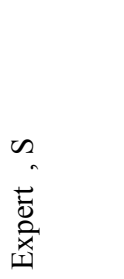 & 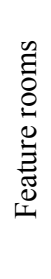 & $\begin{array}{l}\frac{n}{0} \\
\frac{0}{I}\end{array}$ & 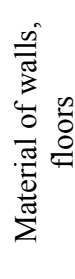 & 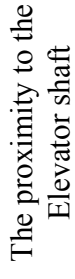 & 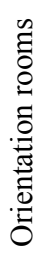 & 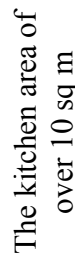 & 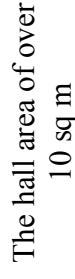 & 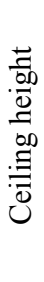 & 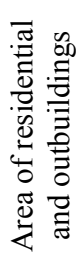 & 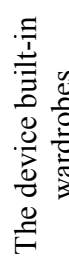 & 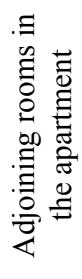 \\
\hline 1 & 1 & 2 & 1 & 1 & 2 & 1 & 2 & 1 & 0 & 2 & 0 \\
\hline
\end{tabular}




\begin{tabular}{|c|c|c|c|c|c|c|c|c|c|c|c|}
\hline 2 & 1 & 2 & 1 & 2 & 0 & 1 & 2 & 1 & 1 & 0 & 0 \\
\hline 3 & 2 & 1 & 1 & 0 & 2 & 2 & 1 & 1 & 1 & 2 & 0 \\
\hline 4 & 0 & 2 & 1 & 1 & 1 & 0 & 2 & 1 & 1 & 1 & 1 \\
\hline 5 & 2 & 1 & 2 & 2 & 0 & 2 & 1 & 2 & 0 & 0 & 0 \\
\hline 6 & 1 & 1 & 2 & 1 & 0 & 1 & 1 & 2 & 2 & 0 & 1 \\
\hline 7 & 2 & 1 & 1 & 1 & 1 & 2 & 1 & 1 & 0 & 1 & 1 \\
\hline 8 & 1 & 2 & 0 & 2 & 2 & 1 & 2 & 0 & 1 & 2 & 0 \\
\hline 9 & 0 & 2 & 1 & 1 & 2 & 0 & 2 & 1 & 1 & 2 & 0 \\
\hline 10 & 1 & 1 & 2 & 2 & 0 & 1 & 1 & 2 & 1 & 0 & 2 \\
\hline 11 & 1 & 0 & 1 & 1 & 2 & 1 & 0 & 1 & 1 & 2 & 0 \\
\hline$\sum_{1}^{11} V_{j s}$ & 12 & 15 & 13 & 14 & 12 & 12 & 15 & 13 & 9 & 12 & 5 \\
\hline$m_{P_{j}}$ & $\frac{N}{0}$ & 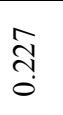 & $\frac{\hat{a}}{0}$ & 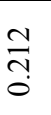 & $\frac{\infty}{\infty}$ & $\frac{\infty}{0}$ & సิ & $\frac{\hat{\sigma}}{0}$ & $\frac{0}{\dddot{0}}$ & $\frac{\pi}{0}$ & $\begin{array}{l}\frac{0}{0} \\
\stackrel{0}{0}\end{array}$ \\
\hline \multicolumn{6}{|c|}{$\begin{aligned} \sum_{1}^{5} m_{P_{j_{s}}}=0.182 & +0.227+0.197+0.212 \\
& +0.182=1\end{aligned}$} & \multicolumn{6}{|c|}{$\begin{aligned} \sum_{1}^{6} m_{P_{j_{s}}}=0.182 & +0.227+0.197 \\
& +0.136+0.182 \\
& +0.076=1\end{aligned}$} \\
\hline$\approx=\sqrt[n]{2}=$ & 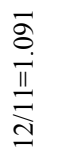 & 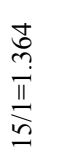 & 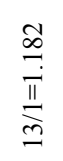 & 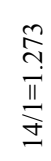 & $\begin{array}{l}\vec{a} \\
\substack{\text { II } \\
\text { à }}\end{array}$ & 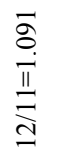 & 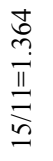 & 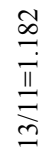 & $\begin{array}{l}\| \frac{\infty}{\Delta} \frac{\infty}{\sigma} \\
\sigma \\
0\end{array}$ & 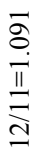 & $\frac{\|}{i n}$ \\
\hline
\end{tabular}

Table 4. An example of defining an integrated index of consumer qualities of the $\mathrm{i}$-th apartment on the basis of estimates of IQI and weights

\begin{tabular}{|c|c|c|c|c|c|}
\hline \multirow{2}{*}{$\begin{array}{l}\text { Code } \\
\text { prop } \\
\text { erties }\end{array}$} & \multirow{2}{*}{\multicolumn{2}{|c|}{ Individual quality indicators (IQI) - $(\mathrm{Pj})$}} & $\begin{array}{l}\text { Average } \\
\text { score }\end{array}$ & Weight & $\begin{array}{l}\text { Final } \\
\text { score }\end{array}$ \\
\hline & & & $q_{P_{j}}$ & $m_{P_{j}}$ & $q_{P_{j}} \cdot m_{P_{j}}$ \\
\hline 100 & \multicolumn{2}{|c|}{ Evaluation of consumer qualities of premises } & & & \\
\hline \multirow[t]{7}{*}{110} & \multicolumn{2}{|c|}{ The location of the apartment in the house } & & & \\
\hline & P1 & Feature rooms & 1.091 & 0.033 & 0.036 \\
\hline & P2 & Floors & 1.364 & 0.041 & 0.056 \\
\hline & P3 & Material of walls, floors & 1.182 & 0.036 & 0.043 \\
\hline & P4 & The proximity to the Elevator shaft & 0.273 & 0.039 & 0.011 \\
\hline & P5 & Orientation rooms & 1.091 & 0.033 & 0.036 \\
\hline & & 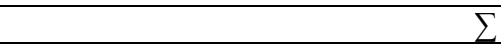 & & 0.182 & 0.182 \\
\hline \multirow[t]{8}{*}{120} & \multicolumn{2}{|c|}{ Space-planning solution of the apartment } & & & \\
\hline & P6 & The kitchen area of over $10 \mathrm{sq} \mathrm{m}$ & 1.091 & 0.041 & 0.045 \\
\hline & P7 & The hall area of over $10 \mathrm{sq} \mathrm{m}$ & 1.364 & 0.052 & 0.071 \\
\hline & P8 & Ceiling height & 1.182 & 0.045 & 0.053 \\
\hline & P9 & Area of residential and outbuildings & 0.818 & 0.031 & 0.025 \\
\hline & P10 & The device built-in wardrobes & 1.091 & 0.041 & 0.045 \\
\hline & P11 & Adjoining rooms in the apartment & 0.455 & 0.017 & 0.008 \\
\hline & & $\sum$ & & 0.227 & 0.247 \\
\hline 130 & \multicolumn{2}{|c|}{$\begin{array}{l}\text { The presence of the glassed balcony(s) loggia } \\
\text { (s) }\end{array}$} & & & \\
\hline & P12 & Area balcony(s) loggia (s) & 0.716 & 0.081 & 0.058 \\
\hline
\end{tabular}




\begin{tabular}{|c|c|c|c|c|c|}
\hline & P13 & $\begin{array}{l}\text { Type of glazing installation, double } \\
\text { glazing }\end{array}$ & 0.534 & 0.081 & 0.043 \\
\hline & & $\sum$ & & 0.197 & 0.101 \\
\hline \multirow[t]{5}{*}{140} & \multicolumn{2}{|c|}{ Bathroom } & & & \\
\hline & P14 & The presence of combined bathroom & 0.678 & 0.042 & 0.028 \\
\hline & P15 & Square bathroom & 0.513 & 0.036 & 0.018 \\
\hline & P16 & Sanitary arrangements & 0.505 & 0.035 & 0.018 \\
\hline & & $x_{0}$ & & 0.136 & 0.064 \\
\hline \multirow[t]{4}{*}{150} & \multicolumn{2}{|c|}{$\begin{array}{l}\text { Improved furnish of premises under the } \\
\text { "European standard" }\end{array}$} & & & \\
\hline & P17 & The need for improved finish & 0.320 & 0.025 & 0.008 \\
\hline & P18 & $\begin{array}{l}\text { The equipment with modern technical } \\
\text { devices }\end{array}$ & 0.534 & 0.024 & 0.013 \\
\hline & & $\sum$ & & 0.076 & 0.021 \\
\hline \multirow[t]{10}{*}{160} & \multicolumn{2}{|c|}{ Sanitary state } & & & \\
\hline & P19 & The microclimate in the apartment & 1.182 & 0.023 & 0.027 \\
\hline & P20 & $\begin{array}{l}\text { Conditions of insolation and artificial } \\
\text { illumination }\end{array}$ & 1.091 & 0.021 & 0.023 \\
\hline & $\mathrm{P} 21$ & The conditions of artificial lighting & 1.364 & 0.024 & 0.033 \\
\hline & P22 & $\begin{array}{l}\text { Organization of space for the } \\
\text { installation of air conditioning }\end{array}$ & 0.818 & 0.018 & 0.015 \\
\hline & $\mathrm{P} 23$ & The view from the window (window) & 0.818 & 0.025 & 0.020 \\
\hline & P24 & The noise level in the apartment & 0.455 & 0.022 & 0.010 \\
\hline & $\mathrm{P} 25$ & The need for repair & 1.091 & 0.030 & 0.033 \\
\hline & & $\sum$ & & 0.182 & 0.161 \\
\hline & & TOTAL: & & 1.000 & 0.776 \\
\hline \multicolumn{6}{|c|}{$\begin{array}{l}\text { Comprehensive index of consumer qualities of the apartment: } \\
\qquad C_{i P_{j}}^{a}=\sum_{1}^{25} q_{P_{j}} \cdot m_{P_{j}}=0.776\end{array}$} \\
\hline
\end{tabular}

Table 5. An example of defining an integrated index of consumer qualities of the $\mathrm{i}$-th house on the basis of estimates of IQI and weights.

\begin{tabular}{|c|c|c|c|c|c|}
\hline \multirow{2}{*}{$\begin{array}{l}\text { Cod } \\
\text { e } \\
\text { prop } \\
\text { ertie } \\
\text { s }\end{array}$} & \multirow{2}{*}{\multicolumn{2}{|c|}{ Individual quality indicators (IQI) - $(\mathrm{Pj})$}} & $\begin{array}{l}\text { Avera } \\
\text { ge } \\
\text { score }\end{array}$ & $\begin{array}{l}\text { Weigh } \\
\mathrm{t}\end{array}$ & $\begin{array}{l}\text { Final } \\
\text { score }\end{array}$ \\
\hline & & & $q_{P_{j}}$ & $m_{P_{j}}$ & $q_{P_{j}} \cdot m_{P_{j}}$ \\
\hline 200 & \multicolumn{2}{|c|}{ Evaluation of the quality of consumer home } & & & \\
\hline \multirow{9}{*}{210} & \multicolumn{2}{|r|}{ Space-planning decision of the house } & & & \\
\hline & P26 & $\begin{array}{l}\text { The device ramps for wheelchairs and people } \\
\text { with limited mobility }\end{array}$ & 1.091 & 0.053 & 0.058 \\
\hline & P27 & Room for bicycles, scooters, wheelchairs & 1.364 & 0.042 & 0.057 \\
\hline & P28 & The presence of a spacious hall in the hallways & 1.182 & 0.022 & 0.026 \\
\hline & P29 & $\begin{array}{l}\text { The possibility of placing concierge doormanin } \\
\text { the entrance }\end{array}$ & 0.818 & 0.035 & 0.029 \\
\hline & P30 & The presence of underground garage & 0.455 & 0.038 & 0.017 \\
\hline & P31 & Exterior facades of the house & 1.091 & 0.046 & 0.050 \\
\hline & P32 & Floors & 1.091 & 0.046 & 0.050 \\
\hline & & 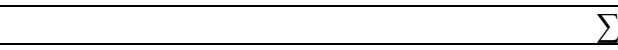 & & 0.282 & 0.287 \\
\hline 220 & \multicolumn{2}{|c|}{ The level of technical furnishing } & & & \\
\hline & P33 & The availability of modern elevators & 1.000 & 0.063 & 0.063 \\
\hline & P34 & Device intercom & 0.818 & 0.052 & 0.043 \\
\hline
\end{tabular}




\begin{tabular}{|c|c|c|c|c|c|}
\hline & P35 & Device video intercom and video camera & 1.343 & 0.032 & 0.043 \\
\hline & P36 & Device automatic sprinkler & 1.182 & 0.045 & 0.053 \\
\hline & P37 & $\begin{array}{l}\text { The device of systems of ventilation and } \\
\text { conditioning }\end{array}$ & 1.102 & 0.039 & 0.043 \\
\hline & & 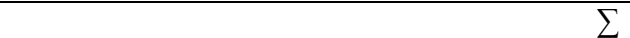 & & 0.231 & 0.245 \\
\hline \multirow[t]{7}{*}{230} & \multicolumn{2}{|c|}{ House territory improvement } & & & \\
\hline & P38 & The possibility of using the adjacent territory & 0.678 & 0.042 & 0.028 \\
\hline & P39 & The availability of Parking machines & 0.513 & 0.036 & 0.018 \\
\hline & $\mathrm{P} 40$ & The playgrounds and sports facilities & 0.505 & 0.035 & 0.018 \\
\hline & $\mathrm{P} 41$ & The presence of fencing the local area & 0.320 & 0.025 & 0.008 \\
\hline & P42 & Gardening and landscaping & 0.534 & 0.024 & 0.013 \\
\hline & & 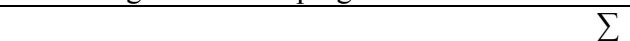 & & 0.162 & 0.085 \\
\hline \multirow[t]{5}{*}{240} & \multicolumn{2}{|c|}{ The proximity to public transport } & & & \\
\hline & $\mathrm{P} 43$ & The proximity to public transport & 0.678 & 0.042 & 0.028 \\
\hline & P44 & The proximity to the metro & 0.513 & 0.036 & 0.018 \\
\hline & $\mathrm{P} 45$ & The proximity to the Railways stations & 0.505 & 0.035 & 0.018 \\
\hline & & (2) p. & & 0.113 & 0.064 \\
\hline \multirow[t]{6}{*}{250} & \multicolumn{2}{|c|}{$\begin{array}{l}\text { The building belongs to the monuments of history, } \\
\text { culture and architecture }\end{array}$} & & & \\
\hline & $\mathrm{P} 46$ & Belonging to the monuments of history & 0.320 & 0.026 & 0.008 \\
\hline & P47 & $\begin{array}{l}\text { The building belongs to the monuments of } \\
\text { culture }\end{array}$ & 0.534 & 0.024 & 0.013 \\
\hline & P48 & The building belongs to the monuments & 0.320 & 0.025 & 0.008 \\
\hline & P49 & Finding a home in the historical buffer zone & 0.534 & 0.024 & 0.013 \\
\hline & & $e^{2}$ & & 0.099 & 0.042 \\
\hline 260 & \multicolumn{2}{|c|}{$\begin{array}{l}\text { The placement of household service enterprises on the } \\
\text { ground floor }\end{array}$} & & & \\
\hline & P50 & Educational facilities & 0.678 & 0.042 & 0.028 \\
\hline & P51 & Allocation of the storage areas & 0.513 & 0.036 & 0.018 \\
\hline & P52 & The location of the office space & 0.505 & 0.035 & 0.018 \\
\hline & & 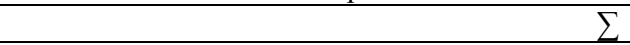 & & 0.113 & 0.064 \\
\hline & & TOTAL: & & 1.000 & 0.787 \\
\hline
\end{tabular}

Comprehensive consumer house quality:

$$
C_{i P_{j}}^{h}=\sum_{26}^{52} q_{P_{j}} \cdot m_{P_{j}}=0.787
$$

Table 6. An example of defining an integrated index of consumer qualities of the i-th district on the basis of estimates of IQI and weights.

\begin{tabular}{|c|c|c|c|c|c|}
\hline \multirow{2}{*}{ 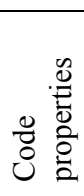 } & \multirow{2}{*}{\multicolumn{2}{|c|}{ Individual quality indicators (IQI) - $(\mathrm{Pj})$}} & $\begin{array}{l}\text { Avera } \\
\text { ge } \\
\text { score }\end{array}$ & $\begin{array}{l}\text { Weigh } \\
t\end{array}$ & $\begin{array}{l}\text { Final } \\
\text { score }\end{array}$ \\
\hline & & & $q_{P_{j}}$ & $m_{P_{j}}$ & $q_{P_{j}} \cdot m_{P_{j}}$ \\
\hline 300 & \multicolumn{2}{|c|}{ Evaluation of consumer qualities of the area } & & & \\
\hline \multirow[t]{5}{*}{310} & \multicolumn{2}{|c|}{$\begin{array}{l}\text { The location of the location of the house relative to the } \\
\text { center of the city }\end{array}$} & & & \\
\hline & P53 & The location of the area in the city & 0.678 & 0.042 & 0.028 \\
\hline & P54 & The time spent on the road & 0.513 & 0.036 & 0.018 \\
\hline & P55 & The number of available modes of transport & 0.505 & 0.035 & 0.018 \\
\hline & & $e^{2}$ & & 0.113 & 0.064 \\
\hline 320 & \multicolumn{2}{|c|}{ The environment } & & & \\
\hline
\end{tabular}




\begin{tabular}{|l|l|l|c|c|c|}
\hline & P56 & The condition of the air environment & 1.000 & 0.063 & 0.063 \\
\hline & P57 & Background radiation & 0.818 & 0.052 & 0.043 \\
\hline & P58 & The presence of industries and businesses & 1.343 & 0.032 & 0.043 \\
\hline & P59 & Proximity to transport routes & 1.182 & 0.045 & 0.053 \\
\hline & P60 & Gardens & 1.102 & 0.039 & 0.043 \\
\hline & & & & 0.231 & 0.245 \\
\hline 330 & The improvement of the district & & & \\
\hline & P61 & $\begin{array}{l}\text { Walking distance to the objects of trade, } \\
\text { consumer services }\end{array}$ & 1.182 & 0.022 & 0.026 \\
\hline & P62 & $\begin{array}{l}\text { Walking distance to objects of education, } \\
\text { culture, sports, leisure }\end{array}$ & 0.818 & 0.035 & 0.029 \\
\hline & P63 & $\begin{array}{l}\text { The improvement district, road surface, } \\
\text { landscaping, lighting, }\end{array}$ & 0.455 & 0.038 & 0.017 \\
\hline & P64 & The presence of the Park, square, pond & 1.091 & 0.046 & 0.050 \\
\hline & P65 & Parking machines & 1.091 & 0.046 & 0.050 \\
\hline & & \multicolumn{2}{|l|}{$\Sigma$} & 0.282 & 0.287 \\
\hline 340 & The individuality of the district & & \\
\hline & P66 & Historical value of residential development & 1.182 & 0.072 & 0.085 \\
\hline & P67 & Ethnic and landscape value of the territory & 0.818 & 0.077 & 0.063 \\
\hline & P68 & $\begin{array}{l}\text { The presence of zones of protection of } \\
\text { historical, cultural and architectural monuments }\end{array}$ & 0.455 & 0.078 & 0.035 \\
\hline & P69 & Density & 1.091 & 0.063 & 0.069 \\
\hline & P70 & Storeys building & 1.091 & 0.084 & 0.092 \\
\hline & & & 0.374 & 0.344 \\
\hline & & & 1.000 & 0.940 \\
\hline & & &
\end{tabular}

Comprehensive index of consumer qualities of the district:

$$
C_{i P_{j}}^{d}=\sum_{53}^{70} q_{P_{j}} \cdot m_{P_{j}}=0.940
$$

Consistency of expert opinion was verified with the value of standard deviation $[16,17]$. Comprehensive quality indicators " $C_{i}$ " characterizing the level of consumer quality of the premises of the i-th residential facility on three levels - apartments, houses, district:

Apartment

$$
\begin{aligned}
C_{i}^{a} & =\sum_{1}^{J} q_{P_{j}} \cdot m_{P_{j}} \\
0 & \leq q_{P_{j}} \leq 2 \\
0 & \leq m_{P_{j}} \leq 1 \\
0 & \leq m_{j} \leq 1
\end{aligned}
$$

House

$$
\begin{gathered}
C_{i}^{h}=\sum_{1}^{J} q_{P_{j}} \cdot m_{P_{j}} \\
0 \leq q_{P_{j}} \leq 2 \\
0 \leq m_{P_{j}} \leq 1 \\
0 \leq m_{j} \leq 1
\end{gathered}
$$

District

$$
\begin{aligned}
C_{i}^{d} & =\sum_{1}^{J} q_{P_{j}} \cdot m_{P_{j}} \\
0 & \leq q_{P_{j}} \leq 2 \\
0 & \leq m_{P_{j}} \leq 1 \\
0 & \leq m_{j} \leq 1
\end{aligned}
$$

Где: $C_{i}^{a}, C_{i}^{h}, C_{i}^{d}$ - comprehensive consumer quality of apartments, houses, area of the i-th residential facility;

q- average rating exposed the experts $\mathrm{Pj}$-th IQI the i-th residential facility;

$\mathrm{i}=1, \mathrm{n}-$ the objects of evaluation;

$\mathrm{j}=1, \mathrm{~J}-$ characteristics included in the IQI;

$P_{j}=\{1 \div P\}-$ the individual indicators of the quality of the IQI assessment objects. 


\section{Conclusions}

To calculate the magnitude of the current market value of a residential facility can be used the integral index of quality of a residential facility. Methodological basis of the calculation remains unchanged, and the accuracy of calculations is high enough. For this we use relative values complex indices of consumer quality residential properties $C_{i}^{o a}, C_{i}^{o h}, C_{i}^{o d}-r_{i}^{o a}$, $r_{i}^{o h}, r_{i}^{o d}$, having them as the quotient of the absolute values of the complex indices on the value of the maximum of the rating scale used $\left(q^{\max }=2\right.$ points $)$ :

$$
r_{i}^{o a}=\frac{C_{i}^{o a}}{q^{\text {max }}} ; r_{i}^{o h}=\frac{C_{i}^{o h}}{q^{\text {max }}} ; r_{i}^{o d}=\frac{C_{i}^{o d}}{q^{\text {max }}}
$$

Obtained three values " $r$ " for each underlying and the estimated object at the three levels comparable because they are derived using the same methodology. The importance of these indicators in the formation of an integrated indicator of quality should be taken into account by the introduction of their weights is "y". This weight should be determined depending on the conditions that determine supply and demand for this type of residential property and the importance for the participant of the real estate market, for example, for the buyer and the seller, each of these conditions. These weights can be obtained from the analysis of the information about the cost of rent and sales of residential properties in the city or area when changed external conditions: the location, highways infrastructure and other factors.

Integral indicator of comparable quality, including estimated residential facility can be determined by the formula:

$$
C_{i}^{\text {int }}=r_{i}^{o a} \cdot y^{o a}+r_{i}^{o h} \cdot y^{o h}+r_{i}^{o d} \cdot y^{o d}
$$

By the proposed technique provides for the calculation $C_{i}^{\text {int }}$ for a number of objects, which had previously conducted evaluation of the transaction of purchase and sale and there is information about selling price (S). These indicators will be used for the valuation of the object. Similarly being an integral indicator of the quality of a residential facility. Of the total number of objects for which received and processed information, selected object, which $S_{i}^{\text {int }} \approx S_{0}^{\text {int }}$. The presence of equality can be considered if the coefficients differ in the magnitude of the accuracy of the calculations by almost 5-7\%. If such an object is, and the price is inserted to the market of the object may be adopted same as that of the analogue.

If this is not unique, then the total number of objects selected two: one with $S_{1}^{\text {int }} \leq S$, another with $S_{2}^{\text {int }} \geq S_{0}^{\text {int }}$.

The cost is calculated based on the assumption that it changes linearly with the values $S^{\text {int }}$ between $S_{1}^{\text {int }}, S_{2}^{\text {int }}$.

Then the estimated value of residential property can be determined by the formula:

$$
S_{0}=S_{1}+\frac{\left(C_{0}^{i n t}-C_{1}^{i n t}\right) \cdot\left(S_{2}-S_{1}\right)}{C_{2}^{i n t}-C_{1}^{i n t}}
$$

Investors, potential buyers, tenants and other entities can calculate according to this method the market value based on an integral quality indicators, characterizing consumer properties, decides on the subsequent use of these objects: purchase, sales, rent, mortgage, etc. In the case that the objects in question do not satisfy the demand in the real estate market, the owner of a residential facility, takes the decision to repair, rebuild or overhaul to improve its consumer properties. 
This technique allows to estimate the current market value of a residential facility based on the level of its consumer qualities before making a decision about capital repairs, reconstruction, and renovation of the facility.

\section{References}

1. C. Duvierac, D. Neagub, C. Oltean-Dumbravaa, D. Dickensc. ,International Journal of Information Management 38, Issue 1, 196-200 (2018)

2. M. Norris. Social Housing Landlords: Europe International Encyclopedia of Housing and Home, 438-443 (2012)

3. A. Beer. Housing Governance, International Encyclopedia of Housing and Home, 497-501 (2012)

4. E. R. Housing Journal of Housing for the Elderly 31, Issue 3 (2017)

5. Joseph T.L., Ooi Thao T.T., Le Nai-JiaLee. Journal of Housing Economics 26 126-138 (2014)

6. Joseph T.L., Ooi1Thao, T.T. Le. Regional Science and Urban Economics 43, Issue 6, 850-861, (November 2013)

7. V. Zahirovich-Herberta, K. M.Giblerb. Journal of Housing Economics 26, 1-18 (2014)

8. E. Nezhnikova, R. Obukhov 08025 MATEC Web Conf. Volume 106 (2017)

9. V. Földváry, G. Bekö, S. Langer, K. Arrhenius, D. Petráš. Building and Environment, Volume 122, 363-372 (2017)

10. 10 N. Safronova, E. Nezhnikova, A. Kolhidov MATEC Web Conf. Volume 106, (2017)

11. E. A. Antipov, E. B. Pokryshevskaya. Mass appraisal of residential apartments: An application of Random forest for valuation and a CART-based approach for model diagnostics. 39, Issue 2, 1, 1772-1778 (2012)

12. D.N. Silka, I.G. Lukmanova, A.A. Afanasev, M.A. Kasyanov, International Journal of Economics and Financial Issues. 5(3s) 121-124 (2015)

13. Kamenetsky M.I. Forecasting problems, 3, 76-91 ( 2013)

14. A.A. Kokoshin, B.I. Bartenev Studies on Russian Economic Development 6, pp. 6-18 (2016)

15. I. Lukmanova, N. Yaskova, Procedia Engineering Volume 165, Pages 1293-1299 (2016)

16. T. Drerupa , B. Enkeb, H-M. Gaudeckerc Journal of Econometrics Volume 200, Issue 2, Pages 378-389 (2017)

17. A. N. Koshev, V. V.Kuzina . Procedia Engineering. Volume 161, Pages 1874-1878 ( 2016) 